NBER WORKING PAPER SERIES

\begin{abstract}
UNEMPLOYMENT, DISEQUILIBRIUM, AND THE SHORT RUN PHILLIPS CURVE:

AN ECONOMETRIC APPROACH
\end{abstract}

\author{
Richard E. Quandt \\ Harvey S. Rosen
}

Working Paper No. 1648

\author{
NATIONAI BUREAU OF ECONOMIC RESEARCH \\ 1050 Massachusetts Avenue \\ Cambridge, MA 02138 \\ June 1985
}

\begin{abstract}
We would like to thank Avner Bar-Ilan and Alan Blinder for useful comments. Financial support from the National Science Foundation is gratefully acknowledged. The research reported nere is part of the NBER's research program in Labor studies. Any opinions expressed are those of the authors and not those of the lational Bureau of Economic Research.
\end{abstract}




\title{
Unempolyment, Disequilibrium, and the Short Run Phillips Curve: \\ An Econometric Approach
}

\author{
ABSTRACT
}

The paper specifies a disequilibrium model for the aggregate labor market consisting of demand and supply functions for labor, an adjustment equation for wages as well as for prices, a transactions equation and, finally, an equation that relates measured unemployment to vacancies and to excess demand. The model has a more sophisticated treatment of dynamics than earlier disequilibrium models, and uses measured unemployment as an endogenous variable. Two of the error terms are assumed to be aerially correlated and the coefficients are estimated by maximum likelihood. The parameter estimates and the goodness-of-fit are satisfactory and the model's implications for the behavior of several important variables are sensible. Excess demand estimates computed in various ways are reasonable. The model is used to estimate the natural rate of unemployment as well as a short run Phillips curve. Finally, the stability properties of the model are añlyzed by considering the eigenvalues of the system; they are found to have moduli less than one.

Richard E. Quandt Department of Economics Princeton university Princeton, NJ 08544

$609-452-4005$
Harvey $S$. Rosen

Department of Economics

Princeton University

Princeton, NJ 08544

$609: 452-4022$ 


\section{Introduction}

Two major approaches to the study of unemployment have been followed. The equilibrium model assumes that real wage rates instantaneously adjust so as to bring the supply and demand of labor into equality. Unemployment is a consequence of erroneous expectations, and/or intertemporal labor supply substitution, and/or government policies such as unemployment insurance. ${ }^{1}$ In contrast, the disequilibrium model allows for the possibility that the real wage may fail to equate the supply and demand of labor. Unemployment occurs when the quantity of labor supplied exceeds the quantity demanded at the going real wage. Typically, in these models it is assumed that the observed quantity of labor during any given period is the minimum of the quantity demanded and the quantity supplied.

In the United States, most empirical work has followed the equilibrium paradigm. Part of the reason may be ideological--failure of markets to clear is generally viewed as concomitant with the failure of some agents to optimize, a notion that is heretical according to the neoclassical religion. Certainly, the inability to articulate a compelling choice-theoretic explanation for real wage stickness is a problem for disequilibrium advocates. ${ }^{2}$ Moreover, disequilibrium models are much more difficult to deal with computationally. Standard econometric software packages generally cannot be used, and difficult nonlinear estimation problems often emerge. As a consequence, disequilibrium models that are quite simple from an economic standpoint are quite complicated computationally. Hence, compared to their equilibrium counterparts, disequilibrium models appear rather 
unsophisticated.

Proponents of disequilibrium models are apt to point out that despite difficulties in explaining precisely why the labor market does not clear at every moment in time, the real world does seem to be like that, and this fact should be reflected in economic analysis. As Rees $[1970, \mathrm{p} \cdot 234]$ observes,

"Although we know very little about the exact nature of the costs of making wage changes, we can infer that they exist. Wages are, next to house rents, the stickiest general class of prices in the economy, seldom adjusted more frequently than once a year. This stickiness may be reinforced by unionism and collective bargaining, but it was present long before unions arrived." .

In this paper we do not attempt to settle the equilibrium versus disequilibrium controversy. ${ }^{3}$ Our goal is rather to put the two types of models on a more equal standing by estimating an economically richer disequilibrium model than has hitherto been studied.

The model, which is presented in Section 2, relates measured unemployment rates to the "true" excess supply of labor, has relatively sophisticated nominal wage and price dynamics, and allows estimation of the short run inflation-employment trade-off. Estimation issues are discussed in Section 3. Among the econometric features of the analysis are the presence of corrections for autocorrelation and the inclusion of non-linearities in the variables. Both of these are difficult to deal with in a disequilibrium context. The model is estimated with annual U.S. data for the period 1929-1979, and the results are analyzed in Section 4. Section 5 concludes with a summary and suggestions for future research. 


\section{The Model}

We consider a system of six equations, one each for the marginal productivity of labor, the supply of labor, the observed quantity of labor, nominal wages, the price level, and the vacancy-unemployment rate relationship. The deterministic version of each equation is discussed in turn. We defer until Section 3 the matter of stochastic specification.

Marginal productivity of labor. Profit maximizing behavior by firms conditional on output leads to a demand function for labor of the form

$$
D_{t}=D\left(W_{t} / P_{t}, Q_{t}, t\right)
$$

where $D_{t}$ is quantity demanded in year $t,\left(W_{t} / P_{t}\right)$ is the real wage, $Q_{t}$ is real output, and $t$ is a time trend. $D_{t}$ is the notional demand in the sense that it is the amount of labor that firms desire to employ at wage $\left(W_{t} / P_{t}\right)--$ not necessarily the quantity they will end up hiring.

For purposes of estimation, a log-linear approximation (except for t) is employed:

$$
\ln D_{t}=\alpha_{0}+\alpha_{1} \ln \left(W_{t} / P_{t}\right)+\alpha_{2} \ln Q_{t}+\alpha_{3} t
$$

Formulation (2.1) (or a minor variant) is a common starting point for studying labor markets (see, for example, Lucas and Rapping [1970], Rosen and Quandt [1978], Romer, [1981], Smyth [undated], and Hajivassiliou [1983]). Nevertheless, ideally one would want to study a 
multi-market model in which output was treated econometrically as an endogenous variable. This task is beyond the scope of the current study, and for tractability it will be assumed that output is exogenous. Note that equation (2.1) assumes that notional demand in a period depends only on other variables during the same period. Given that our data are annual, this does not strike us as unreasonable. Nevertheless, we estimated a variant of the model which included lagged output. As noted below, the coefficient on lagged output was marginally significant statistically, and its inclusion had only a trivial impact on the other coefficients.

Supply of labor. The total number of manhours supplied in year $t$ depends upon the real net wage, $\left(W_{n t} / P_{t}\right)$, and the potential labor force, $H_{t}$, which is essentially a scale variable to. capture the effect of population growth. Again assuming a log-linear specification:

$$
\ln S_{t}=\beta_{0}+\beta_{1} \ln \left(W_{n t} / P_{t}\right)+\beta_{2} \ln H_{t}
$$

where $S_{t}$ denotes notional supply. 4 The basic theory of labor supply suggests that non-labor income belongs in equation (2.2). However, Romer [1981] points out that unearned income is endogenous in a lifecycle model of labor supply determination, and shows that more sensible results can be obtained when it is omitted. Equation (2.2) is very simple in that it ignores the possible role of intertemporal labor supply substitution. Dealing with this problem rigorously requires careful modelling of future wage expectations, a task that is beyond our scope. (See Altonji [1982].) However, some simple expectational models 
$i$ mply that the lagged wage as well as its current value appear in the supply equation. Such a formulation is discussed below.

Observed quantity of labor. In an equilibrium model, the observed quantity of labor is determined by the intersection of the supply and demand curves. 'In a disequilibrium model, this is not the case. In conformity with most of the work in disequilibrium theory, we assume that the quantity observed is the minimum of the quantities supplied and demanded at the current wage:

$$
\operatorname{lnL_{t}}=\min \left(\ell n S_{t}, \quad \ell n D_{t}\right)
$$

Clearly, eq. (2.3) does not describe completely what is presumably a very complicated rationing story, in which some submarkets have excess demand and some have excess supply. (See Hajivassiliou [1983].) However, the simple "min condition" helps keep the problem tractable, and we think that it is a reasonable approximation."

Taken together, eqs. (2.1), (2.2), and (2.3) form the bare bones disequilibrium model. Such equations have been estimated by several investigators, often with the addition of a wage adjustment equation which makes the change in real wages some function of excess demand. (See, for example, Rosen and Quandt [1978].) These studies have demonstrated the computational feasibility of disequilibrium estimation, and indicated the promise that such models have for explaining the time series data.

Still, these models suffer from several deficiencies: (1) They do not show how official unemployment rates and the history of wage and 
price changes might affect current nominal wage rates. (2) They assume that product prices are exogenous. In particular, past changes in nominal wages exert no impact on the current price level. (3) They ignore information in official unemployment rates that might be exploited to help estimate the excess demand for labor. The remaining equations of the model remedy these problems.

Nominal wage adjustment. We assume that this year's nominal wage rate depends upon the last two yearsi nominal wages, upon this year's official unemployment rate $\left(U_{t}\right)$, and upon recent changes in prices:

$$
\begin{aligned}
\ell n W_{t}=\gamma_{0} & +\gamma_{1} \ell n W_{t-1}+\gamma_{2} U_{t}+\gamma_{3}\left(\ell n P_{t}-\ln P_{t-1}\right) \\
& +\gamma_{4}\left(\ln P_{t-1}-\ln P_{t-2}\right)+\gamma_{5} \ln W_{t-2}
\end{aligned}
$$

Lagged wages are included because of the possibility that adjustment to new wage levels is sluggish. The presence of the official unemployment rate reflects the possibility that when the labor market is slack (high $\mathrm{U}_{t}$ ), then nominal wages will be lower, ceteris paribus, and vice versa. Now, it is well known that unemployment as measured in the official statistical series does not correspond well to the theoretical notion of unemployment as the inability to find work at the going wage. Why not, then, include excess demand, $\left(\operatorname{lnD}{ }_{t}-\operatorname{lnS}{ }_{t}\right)$, rather than $U_{t}$ ? The choice of $U_{t}$ reflects the fact that workers and employers do not know $\left(\ell n D_{t}-\ell n S_{t}\right)$; they have to rely on their perceptions of the labor market situation, and these are well-measured by $U_{t}$. Lagged prices are included because of the expectation that workers' 
nominal wage requests will depend on the extent of recent price changes. Ceteris paribus, higher prices will result in high nominal wages. (Indeed, in much of the union sector, indexing is formally built into wage contracts.) The particular lag structure embodied in (2.4) was selected after some experimentation with other formulations. As usual, theory does not give much guidance with respect to the pattern of lags, and eq. (2.4) was superior to several alternatives in the sense of leading to the best fit to the data.

Price adjustment. The price level this period depends upon the lagged price level and the recent history of nominal wage changes:

$$
\ell n P_{t}=\delta_{0}+\delta_{1} \ell n P_{t-1}+\delta_{2}\left(\ell n W_{t}-\ell n W_{t-1}\right)+\delta_{3}\left(\ell n W_{t-1}-\ell n W_{t-2}\right)
$$

The logic here is very similar to that of (2.4). The lagged price term reflects sluggishness in the price adjustment process. Lagged nominal wages are included because producers take factor costs into account when setting their prices. (Such behavior is consistent with, for example, simple mark-up models of pricing behavior.) Note that because we do not attempt to model disequilibrium in the goods market, excess demand does not appear in $(2.5)$.

Vacancy-unemployment relationship. Let $V_{t}$ be the vacancy rate in year $t$ and $U_{t}$ be the official unemployment rate, both measured as fractions. Ignore for the moment that $U_{t}$ does not measure correctly the discrepancy between the amount of labor supplied and the amount workers desire to supply at the prevailing wage. Then by definition, $D_{t}=L_{t}\left(1+V_{t}\right)$ and $S_{t}=L_{t}\left(1+U_{t}\right)$, which imply 


$$
\frac{D_{t}}{S_{t}}=\frac{1+V_{t}}{1+U_{t}}
$$

Taking logarithms

$$
\ln D_{t}-\ln S_{t}=\ln \left(I+V_{t}\right)-\ln \left(I+U_{t}\right)
$$

If $V_{t}$ and $U_{t}$ are fairly small, then a Taylor's approximation gives us

$$
\ln D_{t}-\ln S_{t}=V_{t}-U_{t}
$$

Unfortunately, U.S. annual data for the vacancy rate do not exist for our sample period. Pencavel [1974] suggests that the vacancy rate is a stable function of the unemployment rate which can be approximated by the hyperbolic relationship ${ }^{6}$

$$
v_{t}=\lambda / U_{t}
$$

where $\lambda$ is a parameter. Substituting into (2.6) gives us

$$
\ln D_{t}-\ln S_{t}=\frac{\lambda}{U_{t}}-U_{t}
$$

Eq. (2.8) gives the relationship between the official unemployment rate and the excess demand for labor. It does not hold as an identity because: (a) $U_{t}$ measures the "true" unemployment rate with error, and (b) Eq. (2.7) holds only as an approximation.

\section{Estimation Issues}

In this section we discuss the data and outline the estimation procedure. For purposes of reference we restate the model: 


$$
\begin{aligned}
& \ln D_{t}=\alpha_{0}+\alpha_{1} \ln \left(W_{t} / P_{t}\right)+\alpha_{2} \ln Q_{t}+\alpha_{3} t+u_{1 t} \\
& \ln S_{t}=\beta_{0}+\beta_{1} \ell n\left(W_{n t} / P_{t}\right)+\beta_{2} \ell n H_{t}+u_{2 t} \\
& \ln L_{t}=\min \left(\ell n S_{t}, \ln D_{t}\right) \\
& \ell n W_{t}=\gamma_{0}+\gamma_{1} \ell n W_{t-1}+\gamma_{2} U_{t}+\gamma_{3}\left(\ell n P_{t}-\ell n P_{t-1}\right) \\
& +\gamma_{4}\left(\ell n P_{t-1}-\ell n P_{t-2}\right)+\gamma_{5} \ell n W t-2+u_{3 t} \\
& \ln \mathrm{P}_{t}=\delta_{0}+\delta_{1} \ell n P_{t-1}+\delta_{2}\left(\operatorname{lnW} \ln _{t}-\ell n W-1\right) \\
& +\delta_{3}\left(\ell n W_{t-1}-\ell n W_{t-2}\right)+u_{4 t} \\
& \ln D_{t}-\ln S_{t}=\frac{\lambda}{U_{t}}-U_{t}+u_{5 t}
\end{aligned}
$$

All the equations (except (3.3)) differ from their counterparts above by the addition of the error terms $u_{1}, \ldots, u_{5}$, whose joint distribution is specified below. Appending an error term to the "min condition" is possible in theory, but it leads to a substantial increase in com putational costs.

It is routine to establish that the system (minus eq. (3.3)) satisfies the necessary and sufficient conditions for identifiability in a non-linear system. (See Fisher [1966].)

Data. We describe here briefly the definitions of the variables. The sources and methods of construction are detailed in Appendix 3.

The data are annual observations on the U.S. economy for the years 1929 through 1979. $L_{t}$ is total private hours worked per year expressed in billions. The nominal gross hourly wage measured in dollars, $W_{t}$, 
is formed by dividing total civilian compensation by $L_{t} \cdot Q_{t}$ is gross national product measured in billions of 1972 dollars. $P_{t}$ is the consumer price index, scaled so that the value in 1967 is $100.0 .^{7} \mathrm{H}_{t}$, the potential labor force measured in billions, is constructed by taking the number of people between the ages of 16 and 65 , and multiplying by the average number of hours worked per person. The implicit assumption here is that in any given year, those absent from the labor force can potentially contribute an annual number of hours equal to the average of those in the labor force. 8

The marginal net wage $W_{n t}$, is the product of the gross wage $W_{t}$ and a factor $\left(1-\theta_{t}\right)$, where. $\theta_{t}$ is the average marginal federal income tax rate as computed by Barro and Sahasakul [1983]. Finally, $U_{t}$ is the official unemployment rate as a fraction of the civilian labor force.

Stochastic specification and estimation procedure. Wé assume that the error terms $u_{i t}(i=1, \ldots, 5)$ are distributed normally with mean zero and diagonal covariance matrix with element $\sigma_{i}^{2} \quad(i=1, \ldots, 5)$ on the main diagonal. For our first set of estimates (Model 1), we assume that $E\left(u_{i t} u_{i \tau}\right)=0$ for $i=1, \ldots, 5$ and all $t$ not equal to $\tau$. In Model 2 this assumption is relaxed and the error terms in equations (3.4) and (3.5) are permitted to have first order serial correlation. Typically, serial correlation is ignored in disequilibrium models because its presence in equations involving latent variables tends to render the likelihood function intractable. (For special exceptions, see Laffont and Monfort [1979], Quandt [1982]). For our case, serial 
correlation is introduced in the two equations not involving latent variables, which makes the likelihood complicated but not intractable. To our knowledge, such a generalization has not been attempted before.

For all cases estimation is by maximu likelihood; the relevant derivations are'in Appendix 1. The likelihood functions were maximized numerically, using a variety of optimization algorithms ${ }^{9}$ and numerically evaluated derivatives were employed.

\section{Results}

Parameter Estimates. The maximum likelihood estimates of the system (3.1) - (3.6) are presented in Table 1. Two models are presented: Model 1 is exactly the model given by (3.1) - (3.6); Model 2 is the same with the further assumption that the error terms in (3.4) and (3.5) are serially correlated according to first order Markov processes with coefficients $\rho_{4}$ and $\rho_{3}$ respectively. The second column for each model reports 't-values', i.e., the coefficients divided by their asymptotic standard errors.

Consider first the demand equation. There is very little variation in the estimates across models. The value of $\alpha_{1}$ implies that the demand elasticity with respect to the real wage is -0.64 to -0.67 , estimates within the range reported by Hamermesh [1984] in his survey of labor demand equations. Similarly, the output elasticity of about 0.78 is quite reasonable. The coefficient on $t, \alpha_{3}$, ranges from 0.0025 to 0.0033 , suggesting a very mild positive trend in the demand for labor. All three coefficients are statistically significant at conven- 
$\underline{\text { Table }} \underline{1}$

Coefficient Estimates

\begin{tabular}{|c|c|c|c|c|}
\hline & & I & & \\
\hline & Coefficients & $t$-values & Coefficients & $\mathrm{t}$-values \\
\hline$\alpha_{0}$ & -2.7415 & -7.54 & -2.9395 & -8.01 \\
\hline$\alpha_{1}$ & -0.6387 & -14.87 & -0.6698 & -15.28 \\
\hline$\alpha_{2}$ & 0.7813 & 21.10 & 0.7896 & 21.49 \\
\hline$\alpha_{3}$ & 0.0025 & 1.84 & 0.0033 & 2.41 \\
\hline $\mathrm{B}_{0}$ & 2.4116 & 4.37 & 2.4130 & 4.36 \\
\hline$\beta_{1}$ & 0.1167 & 5.42 & 0.1171 & 5.41 \\
\hline$B_{2}$ & 0.5599 & 6.16 & 0.5601 & 6.14 \\
\hline$\gamma_{0}$ & 0.0843 & 3.53 & 0.2195 & 3.78 \\
\hline$\gamma_{1}$ & 0.9272 & 4.69 & 0.3783 & 2.48 \\
\hline$\gamma_{2}$ & -0.4482 & -2.78 & -1.6644 & -4.64 \\
\hline$\gamma_{3}$ & 0.2934 & 0.49 & 0.3483 & 1.45 \\
\hline$\gamma_{4}$ & 0.4657 & 1.02 & 0.6325 & 2.88 \\
\hline$\gamma_{5}$ & 0.0522 & 0.27 & 0.5407 & 3.69 \\
\hline$\delta_{0}$ & -0.1253 & -3.96 & -0.1297 & -2.39 \\
\hline$\delta_{1}$ & 1.0276 & 139.33 & 1.0303 & 81.46 \\
\hline$\delta_{2}$ & 0.4707 & 2.35 & 0.3281 & 3.39 \\
\hline$\delta_{3}$ & 0.1259 & 1.01 & 0.1452 & 1.98 \\
\hline$\lambda$ & 0.0014 & 8.62 & 0.0014 & 8.70 \\
\hline$P_{4}$ & --- & -- & 0.4436 & 2.95 \\
\hline$\rho_{3}$ & $-\cdots-$ & --- & 0.8703 & 7.76 \\
\hline
\end{tabular}


Table 1 (continued)

$\begin{array}{lllll}\sigma_{1}^{2} & 2.78 \times 10^{-4} & 4.70 & 2.81 \times 10^{-4} & 4.72 \\ \sigma_{2}^{2} & 2.25 \times 10^{-3} & 4.91 & 2.24 \times 10^{-3} & 4.92 \\ \sigma_{3}^{2} & 1.38 \times 10^{-3} & 1.52 & 1.29 \times 10^{-3} & 3.27 \\ \sigma_{4}^{2} & 4.95 \times 10^{-4} & 3.50 & & 3.98 \\ \sigma_{5}^{2} & 4.09 \times 10^{-6} & 0.22 & 5.04 \times 10^{-4} & \\ \log \mathrm{L} & 440.97 & --26 & 4.77 \times 0^{-6} & 0.26 \\ & & & 455.72 & -\cdots\end{array}$


tional levels.

The supply parameters also show substantial stability across models. The elasticity of labor supply with respect to the after-tax wage, $B_{1}$, is about 0.12 . Analyses of time series data have consistentiy found labor supply elasticities that are small in absolute value. The elasticity of labor supply with respect to the potential number of hours, $B_{2}$, is 0.56 , which is lower than one would expect. Even given the fact that the demographic composition of the labor force has changed considerably over time, one still expects that at least roughly, a one percent increase in the potential work force should lead to a one percent increase in labor supply. The reason for the observed result probably lies in the strong collinearity between $H_{t}$ and $W_{n t}$. The simple correlation between the two variables is $0.998 .{ }^{10}$ An ordinary least squares regression of hours worked on $\mathrm{H}_{t}$ alone gives a coefficient on $\mathrm{H}_{t}$ of 0.923 with a standard error of 0.154 .

The parameters of the nominal wage adjustment equation are quite sensitive to whether autocorrelation coefficients are being estimated or not. 11 The coefficient on lagged nominal wages, $\gamma_{1}$, is in the reasonable range from 0.64 to 0.93 . In both models, the coefficient of $U_{t}$, $\gamma_{2}$, is negative, indicating that a higher official unemployment rate is associated with lower nominal wages and conversely. However, with the autocorrelation correction, the absolute value increases substantially (from 0.45 to 1.66 ), and becomes more significant as well. The positive coefficient $r_{3}$ indicates that increases in prices become translated into higher current nominal wage. This effect is again larger and more 
significant in Model 2, although it fails to be significant at the 0.05 leve1. The coefficients of the lagged price change, $\gamma_{4}$, and of the twice lagged wage, $\gamma_{5}$, are relatively small and insignificant in Model 1, and are both significant in Model 2 at conventional levels.

In the price adjustment equation, lagged price has a coefficient of 1.03 in both models. ${ }^{12}$ The values of $\delta_{2}$ and $\delta_{3}$ are positive in both models (and both statistically significant in Model 2), which suggests that lagged changes in nominal wages have a positive effect on this period's prices.

Finally, we turn to the vacancies-unemployment relationship. The only parameter to be estimated here is $\lambda$, whose value is 0.0014 . The positive value is expected: When unemployment increases, the vacancy rate decreases. We discuss below whether the magnitude of the estimated $\lambda$ is sensible.

Comparing Models 1 and 2, it is clear that the standard asymptotic likelihood ratio test rejects Model 1 in favor of Model 2. Hence, in discussing goodness of fit and other issues below, we concentrate on Mode1 2.

Variations on the Basic Model. To assess the robustness of our results, a number of alternative models were estimated. Some of these alternatives are obtained from Model 2 by omitting certain parameters, others by adding some variables and parameters. The alternatives are as follows:

Model 3: Omit $\gamma_{4}, \delta_{3}, \rho_{3}, \rho_{4}$ from Model 2. Model 4: Omit $\gamma_{4}, \delta_{3}, \rho_{3}$ From Model 2 . 
Mode1 5: Omit $\gamma_{4}, \delta_{3}$ from Model 2 .

Model 6: Replace $\lambda / U_{t}$ in equation (3.6) in Mode1 2 by $\lambda_{2} /\left(U_{t}-\lambda_{1}\right)^{t}$.

Model 7: Add to the supply equation in Model 2 the term $B_{3} U B 1_{t}$, where $U B 1_{t}$ is defined as $\mathrm{n}$ [(Unemployment benefits)/CPI + 0.001]. This is responsive to the recent finding by Smyth [undated] that the magnitude of unemployment benefits has a negative impact on labor supply. The term 0.001 is arbitrary and is used to account for the fact that unemployment benefits were zero prior to 1935 .

Model 8: Add to the supply equation in Model 2 the term $\beta_{3}$ UBlt when unemployment benefits are positive and otherwise add the term $\beta_{3} \beta_{4}$, where $\beta_{4}$ is an additional parameter. This is just a slightly different way of introducing the unemployment benefits variable.

Mode1 9: Add to the demand equation in Model 2 the term $\alpha_{4}{ }^{1 n Q} t-1$

Model 10: Add to the supply equation in Model 2 the term $B_{3} \ln \left(W_{t-1} / P_{t-1}\right)$.

\section{Table 2}

Model 2 and Other Models

\begin{tabular}{cc} 
ModeI & Loglikelihood \\
\hline 2 & 455.72 \\
3 & 435.00 \\
4 & 440.70 \\
5 & 450.16 \\
6 & 455.75 \\
7 & 455.91 \\
8 & 455.78 \\
9 & 460.05 \\
10 & 460.83
\end{tabular}

The likelihood values for the various models are reported in Table

Table 2. The conclusion is that Model 2 strongly rejects Models 3, 4 and 5; in turn, Models 6, 7 and 8 are unable to reject Model 2. In particular, the sign of $B_{3}$ is positive in Model 7 , negative in Model 8 
and has a t-value of less than 0.61 in both cases. There appears to be no support for the contention that unemployment benefits influence supply negatively.

With respect to models 9 , and 10 , it appears that on the basis of standard chi-squared tests, the data are consistent with the presence of lagged right hand side variables in the demand and supply equations. Importantly, however, in none of the cases in Table 2 do the parameter estimates differ substantially from those reported in Table 1 . Moreover, the qualitative behavior of the system does not change substantially as a result of those minor parameter changes which do occur. This is very comforting in light of the fact that highly nonlinear systems often generate unstable results. For the sake of simplicity, then, we will continue to base our discussion on the parameters in Table 1 .

Another concern relating to the robustness of our estimates is the possibility that they are driven by the Great Depression, which occurred in the early years of the sample. To investigate this issue we reestimated the model starting with the year 1938 instead of 1929 . The parameters estimates for the 1939-1979 period (which are available upon request to the authors) are substantially the same as those for the 1929-1979 period.

Goodness of Fit. How well does Model 2 "explain" the time series data? To explore this question, we computed for each period the model's prediction for quantity of labor $\left(\ell n L_{t}\right)$, price level $\left(\ell n P_{t}\right)$, nominal wage $\left(\ell_{n} w_{t}\right)$, and official unemployment rate $\left(U_{t}\right) \cdot 13$ For every 
variable, we regressed the actual on the predicted value each period, and then computed the $\mathrm{R}^{2}$. The results are recorded in Table 3 . For all variables, the $R^{2} s$ are high. Of course, this observation does not prove that the model is "right." After all, the current values of $\ell_{n L}$ and $\ell n P_{t}$ depend on their lagged values, and given the high amount of autocorrelation in the data, any macroeconomic model with lagged dependent variables is likely to perform well by this criterion. On the other hand, $\ell n L_{t}$ and $U_{t}$ are not functions of their past values, yet the fit is still pretty good. 14 In short, without making too much of $i t$, we find it comforting that the $R^{2} s$ are reasonably high.

Table 3

$\mathrm{R}^{2} \mathrm{~s}$ for Model 2

Variable

$\frac{\ell n L_{t}}{0.9403} \quad \frac{\ell n P_{t}}{0.9960} \quad \frac{\ell n{ }_{t}}{0.9978} \quad \frac{U_{t}}{0.9112}$

Excess Demand for Labor and Unemployment Predictions. One of the main reasons for estimating a disequilibrium model of the labor market is to produce estimates of excess demand. The strength of excess demand can be measured in several ways:

(i) $\left(\ell n D_{t}-\ell n S_{t}\right)$. The model produces estimates of the logarithms of the notional demand and supply for labor each period. Their difference, the percentage excess demand for labor, provides a measure of unemployment that, in theory, is superior to the official measure. For each period we computed the model's reduced form predic- 
tion of excess demand by substituting the appropriate values of the exogenous and lagged endogenous variables into equations (3.1) - (3.6), solving the entire system for the jointly dependent variables, and com puting $\ell n D_{t}-\ell n S_{t} \cdot 15$

(ii) Simulated Average $\left(\ell \mathrm{nD}_{t}-\ell_{n} S_{t}\right)$. In non-linear systems, the predictions obtained simply by substituting exogenous and pre-determined variables may be misleading. Therefore, we performed some stochastic simulations. (S̄ee Portes, Quandt, Wînter and Yeo [1983].) The simulation strategy was to solve for the jointly determined variables after we added to each structural equation a normal deviate with the same variance as was estimated for that equation. Repeating this procedure 100 times for each time period, we could obtain the average excess demand for each period over the 100 replications.

(iii) $\operatorname{Pr}\left(D_{t}>S_{t} \mid L_{t}\right)$. In some sense, measures (i) and (ii) are point estimates of excess demand. It may be of some interest to know the probability that there was excess demand at all. We therefore compute for each year the probability of excess demand (conditional on the amount of labor.) $)^{16}$

(iv) Simulated Fraction of Times that $D_{t}>S_{t}$. As in (ii) above, we simulated the model 100 times each period, and found the fraction of times that demand exceeded supply.

In Table 4 we display the four measures for each year, as well as the actual official unemployment rate. As expected, the values of all the indicators in 1932-1940 indicate very substantial excess supplies. More generally, all series tell a very similar story qualitatively. 
Table 4

Excess Demand Forecasts

1932

1933

1934

1935

1936

1937

1938

1939

1940

1941

1942

1943

1944

1945

1946

1947

1948

1949

1950

1951

1952

1953

1954

1955

1956

1957

1958

1959

1960

1961

1962

1963

1964

1965

1966

1967

1968

1969

1970

1971

1972

1973

1974

1975

1976

1977

1978

1979

\section{$-0.219$}

$-0.233$

$-0.182$

$-0.206$

$-0.162$

$-0.150$

$-0.171$

$-0.160$

$-0.135$

$-0.067$

0.002

0.139

0.169

0.137

$-0.047$

$-0.068$

$-0.007$

$-0.045$

$-0.050$

$-0.012$

0.012

0.020

$-0.022$

$-0.022$

$-0.030$

$-0.046$

$-0.062$

$-0.050$

$-0.054$

$-0.061$

$-0.050$

$-0.050$

$-0.046$

$-0.038$

$-0.019$

$-0.016$

$-0.012$

$-0.019$

$-0.033$

$-0.039$

$-0.034$

$-0.026$

$-0.032$

0.020

$-0.020$

$-0.008$

0.011

0.032
Simulated
Average

$1 \mathrm{nD}$ - $1 \mathrm{nS}$

$-0.191$

$-0.226$

$-0.194$

$-0.255$

$-0.193$

$-0.169$

$-0.182$

$-0.172$

$-0.145$

$-0.070$

0.001

0.140

0.203

0.193

0.005

$-0.025$

0.042

$-0.028$

0.042

0.002

0.027

0.063

$-0.001$

$-0.005$

$-0.008$

$-0.038$

$-0.056$

$-0.054$

$-0.037$

$-0.058$

$-0.049$

$-0.049$

$-0.047$

$-0.038$

$-0.012$

$-0.015$

$-0.009$

$-0.026$

$-0.035$

$-0.052$

$-0.046$

$-0.048$

$-0.046$

0.005

$-0.047$

$-0.042$

$-0.033$

0.001

$\operatorname{Pr}(D>S(L))$

Simulated

Fraction

of Times

that $D>S$

0.0

0.0

0.0

0.0

0.0

0.0

0.0

0.0

0.0

0.0

0.0

0.0

1.00

1.00

1.00

0.00

0.00

0.08

0.0

0.0

1.00

1.00

1.00

0.0

0.0

0.0

0.0

0.0

0.0

0.0

0.0

0.0

0.0

0.0

0.0

0.08

0.08

0.87

0.99

0.0

0.0

0.0

0.0

0.0

0.0

0.0

0.0

0.0
0.0

0.0

0.0

0.0

0.0

0.0

0.0

0.0

0.0

0.02

0.50

1.00

1.00

1.00

0.45

0.21

0.83

0.21

0.10

0.57

0.73

0.90

0.44

0.43

0.41

0.14

0.03

0.06

0.10

0.03

0.08

0.09

0.10

0.14

0.34

0.32

0.39

0.19

0.16

0.04

0.09

0.07

0.09

0.51

0.04

0.10

0.17

0.51

Actual

$\mathrm{U}$

0.236

0.249

0.217

0.201

0.169

0.143

0.190

0.172

0.146

0.099

0.047

0.019

0.012

0.019

0.039

0.039

0.038

0.059

0.053

0.033

0.030

0.029

0.055

0.044

0.041

0.043

0.068

0.055

0.055

0.067

0.055

0.057

0.052

0.045

0.038 
Both the estimated excess demand and the average excess demand in the simulations are negative in all years except 1942-45, 1952-53, 1979, (and 1978 just for $(1 n D-1 n S)$ ). The somewhat suspect notion of excess demand in 1979 is confirmed by the simulation experiments, which indicate that the probability of excess demand in 1979 is 0.51 . A possible additional reason for preferring model 10 of Table 2 is that its simulated fraction of excess demands for that year drops to 0.07 , a more plausible magnitude.

The probabilities of excess demand by the two measures show fairly substantial agreement with the patterns of excess demand and fair agreement with one another. On the whole, the two excess demand measures and the simulated fraction of times that $D_{t}>S_{t}$ agree better with one another than any of these agrees with $\operatorname{Pr}\left\{D_{t}>S_{t} \mid L_{t}\right\} \cdot$ A probable reason for this discrepancy is that the latter measure is conditional on the observed $L_{t}$ whereas the former three are not. Dynamics and Stability. A question of some interest is whether prices and wages in the model are locally stable. Doubts about the stability of the system might be created by the observation that in the price equation, the coefficient on lagged price, $\delta_{1}$, exceeds one. (See Table 1.) Of course, with a system of difference equations greater than order one, all parameters must be examined simultaneously.

To begin, since equation (3.6) is nonlinear in $U_{t}$, we expand in Taylor series about an arbitrary value $\mathrm{U}_{0}$, yielding

$$
\ell n D_{t}-\ell n S_{t}=\left(-\frac{\lambda}{U_{0}^{2}}-1\right) U_{t}+\text { constant } .
$$

Solving for $U_{t}$, substituting for $D_{t}$ and $S_{t}$ from the demand and supply equations, and then substituting the resulting expression in 
equations (3.4) and (3.5), respectively, yields

$$
\begin{aligned}
\ell n W_{t}=\gamma_{0} & +\gamma_{1} \ell n W_{t-1}-\gamma_{2}\left[\frac{\left(\alpha_{1}-\beta_{1}\right) \ell n W_{t}-\left(\alpha_{1}-\beta_{1}\right) \ell n P_{t}}{1+\lambda / U_{0}^{2}}\right] \\
& +\gamma_{3}\left(\ell n P_{t}-\ell n P_{t-1}\right)+\gamma_{4}\left(\ell n P_{t}-\ell n P_{t-2}\right)+\gamma_{5} \ell n W_{t-2}(4.1) \\
\ell n P_{t}=\delta_{0} & +\delta_{1} \ell n P_{t-1}+\delta_{2}\left(\ell n W_{t}-\ell n W_{t-1}\right)+\delta_{3}\left(\ell n W_{t-1}-\ell n W_{t-2}\right)(4.2)
\end{aligned}
$$

Stability requires that the roots of the characteristic polynomial for the system (4.1), (4.2) lie within the unit circle. As we show in Appendix 2, this condition is satisfied for most plausible values of $\mathrm{U}_{0} \cdot$

Vacancies. Recall equation (2.7), the relationship between the unobserved vacancy rate $\left(V_{t}\right)$, the observed official unemployment rate $\left(U_{t}\right)$, and the parameter $\lambda: V_{t}=\lambda / U_{t}$. Another indicator of the plausibility of our model is whether the magnitudes of the implied values of the vacancy rate are reasonable. To investigate this issue, note from equation (3.6) that vacancies are equal to excess demand plus the official unemployment rate. We can therefore substitute our estimates of $D_{t}, S_{t}$ and $U_{t}$ into (3.6) to calculate $V_{t} \cdot 17$ Given the simple inverse relationship posited between $U_{t}$ and $V_{t}$, we know that $V_{t}$ will be relatively low during the depression, high during World War II, etc. What is reassuring about the results is that the absolute magnitudes seem quite reasonable, something that is not guaranteed by the mere fact that $\lambda>0$. Specifically, from 1932 to 
1940 the estimated vacancy rate is less than 1 percent, during 1943-45 it rises as high as 20 percent and varies between 2 and 6 percent thereafter.

"Natural Rate of Unemployment". Another important feature of any aggregative model of the labor market is its implications for the "natural rate of unemployment" -- the official rate of unemployment that is compatible with constant growth of prices and nominal wages. We impose a constant rate of inflation by requiring $P_{t}-P_{t-1}=W_{t}-W_{t-1}=G$ in equations (3.4) and (3.5), where $G$ is a constant. ${ }^{18}$ Some tedious but straightforward algebra reveals that the official rate of unemployment compatible with these conditions, $U_{t}^{N}$, is the positive root of the equation $\mathrm{AU}_{\mathrm{t}}^{2}+\mathrm{BU}_{\mathrm{t}}+\mathrm{C}=0$, where

$$
\begin{aligned}
A= & \left(\alpha_{1}-\beta_{1}\right) \phi_{5}+1 ; \phi_{5}=\gamma_{2} /\left(1-\gamma_{1}-\gamma_{5}\right) ; \\
B= & \left(\alpha_{1}-\beta_{1}\right)\left(\psi_{2}-\psi_{1}\right)+z_{1 t}-z_{2 t} ; \psi_{2}=\left[\gamma_{0}+\left(\gamma_{3}+\gamma_{4}-\gamma_{1}-2 \gamma_{5}\right)\right] G /\left(1-\gamma_{1}-\gamma_{5}\right) ; \\
& \psi_{1}=\left[\delta_{0}+\left(\delta_{2}+\delta_{3}-\delta_{1}\right) G\right] /\left(1-\delta_{1}\right) ; \\
C= & \lambda ;
\end{aligned}
$$

and $z_{1 t}$ and $z_{2 t}$ are defined as in Appendix 1.

In some macroeconomic models, $U_{t}^{N}$ is required to be independent of the value of $G$. That requirement is not imposed here, so we compute $U_{t}^{N}$ for several values of $G$. Substituting 1979 magnitudes for the variables into (4.3) and values of $G$ equal to $0.0,0.03$ and 0.05 , yields values of $U_{t}^{N}$ of $7.6,4.3$, and 2.3 percent, respectively. It also turns out that the natural rate declines almost monotonically from the 1930's to the present, suggesting that the unavoidable unemployment 
cost of price and wage stability is declining. We conjecture that this result is driven by the very high rates of unemployment during the $1930^{\prime} \mathrm{s} \cdot$

A related question is what level of official unemployment would be associated with "true" zero excess demand in the labor market -$\left(D_{t}-S_{t}\right)=0$. To compute this figure, we simply note from equation (3.6) that when $D_{t}=S_{t}, \frac{\lambda}{U_{t}}-U_{t}=0$, and $f$ ind the $U_{t}$ that satisfies this relationship. According to this calculation, when official unemployment is about 3.7 percent, the labor market is actually in equilibrium.

"Phillips Curve". What does our model imply about the short run trade-off between official unemployment and wage inflation? Of course, these two variables are jointly determined, so it does not make sense simply to plug in the value of one and find the implied value of the other. Instead, we consider how both would move under alternative aggregate demand policies. Specifically, the exogenous values of the model except output $\left(Q_{t}\right)$ are set equal to their 1979 values. We then substitute a number of hypothetical values for $Q_{1979}$ into the system, some higher than the actual value in 1979, and some lower. For every value of $Q_{1979}$, the model is solved to find the associated values of $U_{1979}$ and $\left(\ell n W_{1979}-\ell n W_{1978}\right)$. The results represent an almost Iinear relationship characterized by the equation $(\Delta \mathrm{W} / \mathrm{W})=-2.06 \mathrm{U}+0.19$. To attain a nominal wage growth of only 3.7 percent could require an official unemployment rate of 7.4 percent. Alternatively, if the official unemployment rate were 3.4 percent, one would expect nominal wage 
growth of 12.0 percent. The (approximate) equations for the Phillips curve for other years in the $1970^{\prime}$ 's are very similar.

The conceptual experiment behind these calculations concerns the short run trade-off between $U$ and $(\Delta W / W)$. It is now widely agreed that in the long run, the rate of unemployment is independent of the inflation rate. Although we considered imposing this constraint on the model, we ultimately decided that a better strategy would be to let the data determine the coefficients, and to refrain from giving these estimates a long run interpretation.

\section{Conclusions}

We have specified and estimated an aggregate disequilibrium model of the labor market which allows determination of nominal wages, prices, labor demand and supply, and the official unemployment rate. The parameter estimates are quite reasonable; the system provides a good fit to the data; and its implications for the behavior of several important variables are sensible. Of course, more remains to be done. Two of the more vexing problems in the current model are the exogeneity of output and the absence of any important role for expectations. Work is currently under way to remedy these problems.

This research also demonstrates that despite the fact that the computational burden of estimating disequilibrium models is high, such models can successfully be estimated at reasonable cost. This is true even for systems that go beyond the "bare bones" approach of earlier papers. We hope that this knowledge will encourage other investigators. 


\section{Appendix 1. Derivation of Likelihood Functions}

1. The Basic Model. For the sake of simplifying the notation, $D_{t}, S_{t}, w_{t}, P_{t}$ will denote in this appendix the natural logarithm of demand, supply, nonimal wage and price respectively. $U_{t}$ denotes the measured unemployment rate and $z_{1 t}, z_{2 t}, z_{3 t}, z_{4 t}$ are linear functions of predetermined variables and coefficients. The model can then be written as

$$
\begin{aligned}
D_{t} & =\alpha_{1} w_{t}-\alpha_{1} p_{t}+z_{1 t}+u_{1 t} \\
s_{t} & =\beta_{1} w_{t}-\beta_{1} p_{t}+z_{2 t}+u_{2 t} \\
L_{t} & =\min \left(D_{t}, s_{t}\right) \\
w_{t} & =r_{2} U_{t}+\gamma_{3} p_{t}+z_{3 t}+u_{3 t} \\
p_{t} & =\delta_{2} w_{t}+z_{4 t}+u_{4 t} \\
D_{t}-s_{t} & =\lambda / U_{t}-U_{t}+u_{5 t}
\end{aligned}
$$

where

$$
\begin{aligned}
& z_{1 t}=\alpha_{0}+\alpha_{2} \ln Q_{t}+\alpha_{3} t \\
& z_{2 t}=\beta_{0}+\beta_{1}\left(1-\theta_{t}\right)+\beta_{2} \ln H_{t} \\
& z_{3 t}=\gamma_{0}+\gamma_{1} w_{t-1}-\gamma_{3} p_{t-1}+\gamma_{5} w_{t-2} \\
& z_{4 t}=\delta_{0}+\delta_{1} p_{t-1}-\delta_{2} w_{t-1}
\end{aligned}
$$

Assuming that $u_{1 t}, \ldots,{ }^{11_{5 t}}$ are jointly normal with mean vector zero and diagonal covariance matrix, the joint probability density function of $\left(D_{t}, S_{t}, w_{t}, P_{t}, U_{t}\right)$ is 


$$
\begin{aligned}
& f\left(D_{t}, S_{t}, w_{t}, P_{t} U_{t}\right)=\frac{\left|\Delta_{t}\right|}{(2 \pi)^{5 / 2} \sigma_{1} \sigma_{2} \sigma_{3} \sigma_{4} \sigma_{5}} \exp \left\{-\frac{1}{2}\left[\frac{\left.D_{t}-\alpha_{1} w_{t}+\alpha_{1} P_{1}-z_{1 t}\right)^{2}}{\sigma_{1}^{2}}\right.\right. \\
& +\frac{\left(s_{t}-B_{1} w_{t}+\beta_{1} p_{t}-z_{2 t}\right)^{2}}{\sigma_{2}^{2}}+\frac{\left(w_{t}-\gamma_{2} U_{t}-\gamma_{3} p_{t}-z_{3 t}\right)^{2}}{\sigma_{3}^{2}} \\
& \left.\left.+\frac{\left(p_{t}-\delta_{2} w_{t}-z_{4 t}\right)^{2}}{\sigma_{4}^{2}}+\frac{\left(D_{t}-s_{t}-\lambda_{2} / U_{t}+U_{t}\right)^{2}}{\sigma_{5}^{2}}\right]\right)
\end{aligned}
$$

where $\Delta_{t}$ is the Jacobian of the transformation $\left(\lambda_{2} / U_{t}+1\right)\left(1-\delta_{2} \gamma_{3}\right)$ $-\alpha_{1} \gamma_{2} \delta_{2}+\alpha_{1} \gamma_{2}+\beta_{1} \gamma_{2} \delta_{2}-\beta_{1} \gamma_{2}$. The required density is $h\left(L_{t}, w_{t}, P_{t} ; D_{t}\right)=\int_{L_{t}}^{\infty} f\left(D_{t}, L_{t}, w_{t}, P_{t}, U_{t}\right) d D_{t}+\int_{L_{t}}^{\infty} f\left(L_{t}, S_{t}, w_{t}, P_{t}, U_{t}\right) d S_{t} \cdot$ (A.8)

Deflne further

$$
\begin{aligned}
& z_{5 t}=B_{1} w_{t}-\beta_{1} P_{t}+z_{2 t} \\
& z_{6 t}=L_{t}-\lambda_{2} / U_{t}+\sigma_{t} \\
& z_{7 t}=\alpha_{1} w_{t}-\alpha_{1} P_{t}+z_{1 t} \\
& z_{8 t}=L_{t}+\lambda_{2} / J_{t}-U_{t} \\
& \phi_{1}^{2}=\frac{\sigma_{2}^{2} \sigma_{5}^{2}}{\sigma_{2}^{2}+\sigma_{5}^{2}}
\end{aligned}
$$




$$
\phi_{2}^{2}=\frac{\sigma_{1}^{2} \sigma_{5}^{2}}{\sigma_{1}^{2}+\sigma_{5}^{2}}
$$

$$
\begin{gathered}
A_{t}=\frac{\sigma_{5}^{2} z_{5 t}+\sigma_{2}^{2} z_{6 t}}{\sigma_{5}^{2}+\sigma_{2}^{2}} \quad B_{t}=\frac{\sigma_{5}^{2} z_{5 t}^{2}+\sigma_{2}^{2} z_{6 t}^{2}}{\sigma_{5}^{2}+\sigma_{2}^{2}} \\
C_{t}=\frac{\sigma_{5}^{2} 7 t+\sigma_{1}^{2} z t}{\sigma_{5}^{2}+\sigma_{1}^{2}} \quad F_{t}=\frac{\sigma_{5}^{2} z_{7 t}^{2}+\sigma_{1}^{2} z_{8 t}^{2}}{\sigma_{5}^{2}+\sigma_{1}^{2}}
\end{gathered}
$$

Performing the integrations indicated in (A.7) yields

$$
h\left(L_{t}, w_{t}, P_{t}, U_{t}\right)=G_{1 t}\left(G_{2 t} G_{3 t}+G_{4 t} \cdot G_{5 t}\right)
$$

where

$$
\begin{aligned}
& \left.G_{I t}=\frac{\left|\Delta_{t}\right|}{2 \pi \sigma_{3} \sigma_{4}} \exp \left\{-\frac{1}{2} \cdot \frac{\left(w_{t}-\gamma_{2} U_{t}-\gamma_{3} p_{t}-z_{3 t}\right)^{2}}{\sigma_{3}^{2}}+\frac{\left(p_{t}-\delta_{2} w_{t}-z_{4 t}\right)^{2}}{\sigma_{4}^{2}}\right]\right\} \\
& \left.G_{2 t}=\frac{1}{(2 \pi)^{1 / 2} \sigma_{1}} \exp \left\{-\frac{1}{2}\left[\frac{\left(L_{t}-z_{7 t}\right)^{2}}{2}\right]\right)\right\} \\
& G_{3 t}=\frac{1}{(2 \pi)^{1 / 2}\left(\sigma_{2}^{2}+\sigma_{5}^{2}\right)^{1 / 2}} \exp \left\{-\frac{1}{2 \phi_{1}^{2}\left(B_{t}-A_{t}^{2}\right)}\left[1-\Phi\left(\frac{L_{t}-A_{t}}{\phi_{1}}\right)\right]\right\}
\end{aligned}
$$




$$
\begin{aligned}
& G_{4 t}=\frac{1}{(2 \pi)^{1 / 2} \sigma_{2}} \exp \left\{-\frac{1}{2}\left[\frac{\left(L_{t}-z_{5 t}\right)^{2}}{\sigma_{2}^{2}}\right]\right\} \\
& G_{5 t}=\frac{1}{(2 \pi)^{1 / 2}\left(\sigma_{1}^{2}+\sigma_{5}^{2}\right)^{1 / 2}} \exp \left(-\frac{1}{2 \phi_{2}^{2}}\left(E_{t}-C_{t}^{2}\right)\right)\left[1-\Phi\left(\frac{L_{t}-C_{t}}{\phi_{2}}\right)\right] \\
& \Phi(\omega)=\int_{-\infty}^{\omega} \frac{1}{\sqrt{2 \pi}} e^{-x^{2} / 2} d x
\end{aligned}
$$

The loglikelthood then is

$$
L=\sum_{t} \log h\left(I_{t}, w_{t}, P_{t}, U_{t}\right)
$$

2. Autocorrelated Error Terms. We assume that $u_{3 t}$ and $u_{4 t}$

follow first order Markov processes $u_{3 t}=\rho_{3} u_{3 t-1}+\varepsilon_{3 t}, u_{4 t}=$ $P_{4}^{u} u_{4 t-1}+\varepsilon_{4 t}$. Hence, denoting by $u_{i}$ and $\varepsilon_{1}$ the vectors of errors $(i=3,4)$, we can write

$$
R_{1} u_{1}=\varepsilon_{1} \quad 1=3,4
$$

where

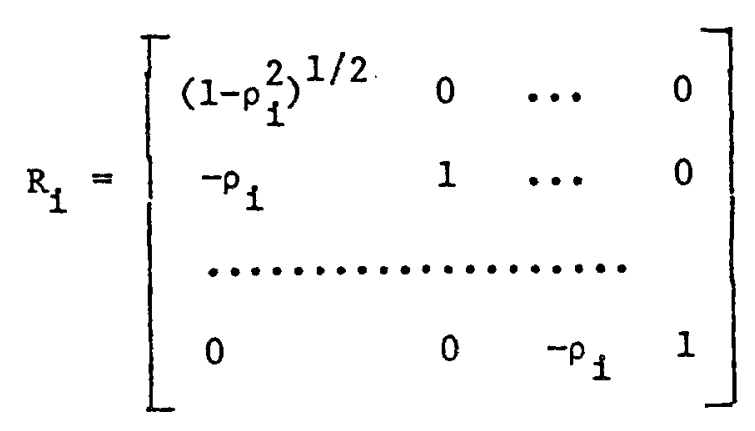


Transforming from the $\varepsilon$ 's to the u's alters only $G_{1 t}$. In analogy with single equation models, the first term is unchanged except for the introduction of $\left(1-\rho_{i}^{2}\right)^{1 / 2}$ into the Jacobian and of $\left(1-\rho_{i}^{2}\right)$ into the matching term of the exponent. In the other terms each squared residual in the exponent is replaced by the square of that residual minus its lagged value which has been multiplied by the matching $\rho_{i}$. 


\section{Appendix 2. The Characteristic Equation}

Let $E$ be the forward operator such that $E x_{t}=x_{t+1}$. Then the characteristic matrix for system $(4.1),(4.2)$ is

$$
\left[\begin{array}{cc}
\left(1+\frac{\gamma_{2}\left(\alpha_{1}-\beta_{1}\right)}{1+\lambda / U_{0}^{2}} E^{2}\right)-\gamma_{1} E-\gamma_{5} & \left(-\gamma_{3}-\frac{\gamma_{2}\left(\alpha_{1}-\beta_{1}\right)}{{ }^{2}}\right) E^{2}+\left(\gamma_{3}-\gamma_{4}\right) E+\gamma_{4} \\
-\delta_{2} E^{2}+\left(\delta_{2}-\delta_{3}\right) E+\delta_{3} & E^{2}-\delta_{1} E
\end{array}\right],
$$

and its characteristic polynomial is

$$
\begin{aligned}
& {\left[1-\delta_{2} \gamma_{3}+\frac{\gamma_{2}\left(\alpha_{1}-\beta_{1}\right)}{1+\lambda / U_{0}^{2}}\left(1-\delta_{2} \gamma_{2}\right)\right] x^{4}+\left[-\gamma_{1}-\delta_{1}+\gamma_{3}\left(\delta_{2}-\delta_{3}\right)-\frac{\gamma_{2}\left(\alpha_{1}-\beta_{1}\right)}{1+\lambda / U_{0}^{2}}\left(\delta_{1}+\delta_{2}-\delta_{3}\right)\right] x^{3}} \\
& +\left[\delta_{1} \gamma_{1}-\gamma_{5}+\delta_{2} \gamma_{4}-\left(\delta_{2}-\delta_{3}\right)\left(\gamma_{3}-\gamma_{4}\right)+\delta_{3}\left(\gamma_{3}+\frac{\gamma_{2}\left(\alpha_{1}-\beta_{1}\right)}{1+\lambda / U_{0}^{2}}\right] x^{2}\right] \\
& +\left[\delta_{1} \gamma_{5}-\delta_{3}\left(\gamma_{3}-\gamma_{4}\right)-\gamma_{4}\left(\delta_{2}-\delta_{3}\right)\right] x-\gamma_{4} \delta_{3}=0
\end{aligned}
$$

The roots of $(A .11)$ depend on the assumed value $U_{0}$ about which the expansion is taken. They were computed for $U_{0}=0.01, \ldots, 0.20$. For all of these cases there is one positive root, one negative root and a pair of complex conjugates. The maximal modulus declines monotonically from 0.8797 for $U_{0}=0.01$ to 0.4585 for $U_{0}=0.20$. The system is thus locally stable for most plausible unemployment rates. It requires an unemployment rate $U_{0}=0.002$ to produce a maximal modulus of 1.0028 . 


\section{Appendix 3. Data}

This appendix describes the sources and methods of construction of the variables in the model. Throughout, we abbreviate "National Income and Product Accounts of the United States" as "N.I.P.A.".

$\mathrm{L}_{t}$, total civilian hours worked per year expressed in billions, is total hours minus hours worked in the military. For 1948-79, the following procedure is used. To find hours worked in the military, compute the ratio of the number of military workers to the total number of government workers (N.I.P.A. 1929-1976, pp. 267-69 and N.I.P.A. 1976-1979, p. 55) and multiply by the number of hours worked by government employees (N.I.P.A. 1929-1976, p. 271 and N.I.P.A. 1976-1979, p. 56). This gives hours worked in the military, which is then subtracted from total hours (N.I.P.A. 1929-1976, p. 271, N.I.P.A. 1976-1979, p. 55).

For 1929-42, comparable data do not exist. Using slightly different methods, Rosen and Quandt (1978) constructed a series on civilian hours extending back to 1929. To splice the two series together, for the period 1948 to 1973 we estimated a regression of the logarithm of civilian hours as calculated above on a time trend and on the logarithm of the Rosen-Quandt measure. The $R^{2}$ was 0.992 . We then substituted values of the Rosen-Quandt measure for 1929 to 1947 into the regression equation, and used the fitted values.

$W_{t}$, gross hourly nominal wage measured in dollars, is the ratio of 
total civilian compensation to civilian hours worked. Total civilian compensation in total compensation of employees (N.I.P.A. 1929-1976, Pp. 238-42 and N.I.P.A. 1976-1979, p. 52) minus compensation of military employees (Historical Statistics of the United States, p. 235; N.I.P.A. 1929-1976, P. 240-42; N.I.P.A. 1976-1979, p. 52). The computation of civilian hours worked is described above.

$Q_{t}$, gross national product in 1972 prices, is from the Economic Report of the President 1982, p. 234, for 1941 through 1979. For previous years, the figures are from Historical Statistics of the United States, p. 224. The figures in Historical Statistics were converted from 1958 dollars to 1972 dollars by using the implicit GNP deflator. $P_{t}$, the consumer price index, is from Historical Statistics of the United States, pp. 210-11 for years prior to 1970; and from Economic Report of the President 1982, p. 291, for years after 1970. $P_{1967}=100.0$.

$\mathrm{H}_{t}$, the potential labor force in billions of hours, is the number of civilians between the ages of 16 and 65 multiplied by the average number of hours worked per person. The number of civilians in this age group is calculated by taking the total population between 16 and 65 (Economic Report of the President 1981, p. 263) and subtracting membership in the armed forces (Ibid., p. 264).

$\theta_{t}$, the average marginal tax rate is taken from Barro and Sahasakul $[1983, \mathrm{p} \cdot 20]$.

$\mathrm{U}_{t}$, unemployment as a percentage of the civilian labor force is from Historical Statistics of the United States (p. 135) for 1929-47, and from Economic Report of the President 1982 (p. 271) for 1948-1979. 


\section{References}

Altonji, Joseph G., "The Intertemporal Substitution Model of Labour

Market Fluctuations: An Empirical Analysis," Review of Economic Studies XIIX, 1982, 783-824.

Barro, Robert J. and Chaipat Sahasakul, "Measuring the Average Marginal

Tax Rate from the Individual Income Tax," National Bureau of

Economic Research, Working Paper No. 1060, January, 1983.

Burkett, J.P., "Marginal and Conditional Probabilities of Excess

Demand," Economics Letters 8, 1981, 159-162.

Chow, Gregory C., "A Reformulation of Simultaneous Equation Models of Markets in Disequilibrium," Economic Research Program, Research Memo No. 5, Princeton University, 1977.

Fisher, Franklin M., The Identification Problem in Econometrics. New York, McGraw-Hill, 1966.

Goldfeld, S.M. and R.E. Quandt, "Single Market Disequilibrium," The Economic Studies Quarterly XXXII, 1981, 12-28.

Hajivassiliou, V.A., "Estimating and Testing An Aggregative Disequilibrium Model of the U.S. Labour Market," M.I.T., Mimeo, April, 1983.

Hamermesh, Daniel S., "The Demand for Labor in the Long Run," National Bureau of Economic Research, Working Paper No. 1297, March, 1984. Laffont, J.-J. and A. Monfort, "Disequilibrium Econometrics in Dynamic Models," Journal of Econometrics 11, 1979, 353-361. 
Lucas, R., and L. Rapping, "Real Wages, Employment and Inflation," in Edmund Phelps, ed., Microeconomic Foundations of Employment and Inflation Theory. New York, 1970.

Pencavel, John H., "A Note on the Use of Unemployment and Vacancy Statistics to Measure Some Effects of Government Legislation," mimeo, Stanford University, 1974.

Portes, R., R.E. Quandt, D. Winter, S. Yeo, 'Macroeconomic Planning and Disequilibrium: Estimates for Poland, 1955-1980," Discussion Paper No. 139, Birkbeck College, London, 1983.

Quandt, Richard E., "Autocorrelated Errors in Simple Disequilibrium Models," Economics Letters 7, 1981, 55-62.

Rees, Albert, "The Phillips Curve as a Menu for Policy Choice," Economica 37, August, 1970, 227-38.

Romer, David, "Rosen and Quandt's Disequilibrlum Model of the Labor Market: A Revision," Review of Economics and Statistics LXII, 1981, $145-146$.

Rosen, Harvey S. and Richard E. Quandt, "Estimation of a Disequilibrium Aggregate Labor Market," The Review of Economics and Statistics, vol. LX, No. 3, August, 1978, 371-379. Sarantis, N., "Employment, Labor Supply and Real Wages in Market Disequilibrium," Journal of Macroeconomics 3, 1981, 335-354. Smyth, David J., "Unemployment Insurance and Labor Supply and Demand: A Time Series Analysis for the United States," Wayne State University, Mimeo, undated.

Stiglitz, Joseph E., "Equilibrium Wage Distributions," National Bureau of Economic Research, Working Paper No. 1337, April, 1984. 


\section{Footnotes}

${ }^{1}$ See, for example, Lucas and Rapping [1970].

${ }^{2}$ There have been a number of attempts along these lines. See, e.g., Stiglitz [1984].

${ }^{3}$ One reason for the difficulty in settling the question statistically is that sophisticated versions of either model may not be conveniently nested within each other. Rosen and Quandt [1978] examine very simple equilibrium and disequilibrium models, and find that the latter does a better job of explaining the data.

${ }^{4}$ We also estimated some versions of $(2.2)$ which include as a variable the unemployment insurance replacement rate. (See Smyth [undated].) As noted below, this had no effect on our substantive results.

${ }^{5}$ An alternative notion of disequilibrium has been suggested by Chow [1977] and implemented by Sarantis [1981]. Here disequilibrium is modelled not by a "min condition", but as a situation in which both prices and quantities adjust slowly each period to their long run values. There is no point in engaging in a semantic discussion of which is the "real" disequilibrium model. Suffice it to say that very different maintained hypotheses are used.

${ }^{6}$ We experimented with the more general formulation $v_{t}=\lambda_{2} /\left(U_{t}-\lambda_{1}\right)+\lambda_{3}$, and found that it did not significantly increase the explanatory power of the model. 
${ }^{7}$ Hajivassiliou $[1983$, p. 20] argues that in the demand for labor equation, the wage should be deflated by the producers' price index. However, he finds that the choice has virtually no effect on the parameter estimates.

${ }^{8}$ We also examined a specification in which $H_{t}$ was simply the number of people between the ages of 16 and 65 ; no major differences resulted.

${ }^{9}$ Algorithms DFP, GRADX and PATERN in the optimization package GQOPT3 were employed.

${ }^{10}$ However, caution must be exercised, because the diagnosis and consequences of multicollinearity in nonlinear models are not obvious.

$1 I_{\text {Note that when }} u_{3 t}$ is serially correlated, the constant term in the differenced form of the equation is $\gamma_{0}\left(1-\rho_{3}\right)=0.028$.

12 The fact that $\delta_{1}>1$ does not necessarily imply that the model is unstable. To determine this, the whole system must be analyzed, as is done below.

${ }^{13}$ This was done by substituting the appropriate values of the exogenous and predetermined variables into (3.1) - (3.6), and solving for the endogenous variables. The value of $L_{t}$ was the minimum of the $S_{t}$ and $D_{t}$ so generated. To solve for $U_{t}$ we: (i) solve for $D_{t}, S_{t}$, $W_{t}, P_{t}$ in terms of $U_{t}$; (ii) substitute the results for $D_{t}$ and $S_{t}$ in the unemployment vacancies relation, and then (iii) solve the resulting quadratic for $U_{t}$.

${ }^{14} \mathrm{~A}$ simple second order autoregression explains $U_{t}$ slightly worse than the disequilibrium model $\left(R^{2}=0.8996\right)$, while a second order 
autoregression explains $L_{t}$ slightly better $\left(R^{2}=0.9528\right)$.

${ }^{15}$ One may also compute $E\left(\ell n D_{t}-\ell n S_{t} \mid \ell n L_{t}\right)$. This is likely to be more efficient than using simply $\left(\ell n \hat{D}_{t}-\ell n \hat{S}_{t}\right)$ (Goldfeld and Quandt (1981)), but is somewhat complicated to compute in the present model and will not be pursued here.

${ }^{16} \operatorname{Pr}\left\{D_{t}>S_{t} \mid L_{t}\right\}$ is computed as the ratio $G_{4 t} G_{5 t} /\left(G_{2 t} G_{3 t}+\right.$ $\left.G_{4 t} G_{5 t}\right)$, where the $G_{t}$ 's are defined in Appendix 1. One can also compute unconditional probability that $D_{t}$ exceeds $S_{t}$. This can be obtained from the reduced form as follows. Let $\mathrm{D}_{t}=\mathrm{H}_{1 \mathrm{t}}+\mathrm{v}_{1 \mathrm{t}}$, $\mathrm{S}_{t}=\mathrm{H}_{2 t}+\mathrm{v}_{2 t}$, where $\mathrm{H}_{1 \mathrm{t}}, \mathrm{H}_{2 \mathrm{t}}$ depend only on parameters and coefficients and $v_{1 t}, v_{2 t}$ are reduced form errors. Then the required probability is $\operatorname{Pr}\left\{\mathrm{H}_{1 t}-\mathrm{H}_{2 t}>\mathrm{v}_{2 t}-\mathrm{v}_{1 t}\right\}$ which can be computed once the estimated parameter values are substituted. However, in some applications these probabilities have been found to be very close to the conditional probabilities. (See Burkett [1981].)

17 When we substitute actual rather than estimated values of the official unemployment rate, qualitatively similar results emerge.

18Note that under this assumption, it follows from equation (2.4) that $U_{t}$ will generally depend on both the level of the real wage and the rate of inflation. However, if $\gamma_{1}+\gamma_{5}=1$, then $U_{t}$ depends only on $G$, a much more plausible result. Note from Table 1 that the sum does appear to be quite close to unity. Indeed, when we imposed the constraint $\gamma_{1}+\gamma_{5}=1$ in model 2, the loglikelihood was 455.25, indicating that the data are compatible with the constraint. 